\title{
Therapy Delayed is Therapy Denied: A Case Report of Melanoma Misdiagnosed as Diabetic Foot Ulcer
}

\author{
Lawrence Chukwudi Nwabudike (D) ${ }^{1}$ * \\ Ana Maria Oproiu iD ${ }^{2,3, *}$ \\ loana Mihaela Dogaru $2,3, *$ \\ Mariana Costache ID $^{2,4, *}$ \\ Cristian Onisor (iD ${ }^{5}$ \\ Alin Laurentiu Tatu (iD) ${ }^{5-7}$ \\ 'N. Paulescu National Institute of \\ Diabetes, Bucharest, Romania; ${ }^{2} \mathrm{Carol}$ \\ Davila University of Medicine and \\ Pharmacy, Bucharest, Romania; \\ ${ }^{3}$ Department of Plastic Surgery, \\ Emergency University Hospital, \\ Bucharest, Romania; ${ }^{4}$ Department of \\ Pathology, Emergency University \\ Hospital, Bucharest, Romania; ${ }^{5}$ Clinical \\ Medical Department, Faculty of Medicine \\ and Pharmacy, Dunarea de Jos University \\ of Galati, Galati, 800008, Romania; \\ ${ }^{6}$ Dermatology Department, 'Sf. Cuvioasa \\ Parascheva' Clinical Hospital of Infectious \\ Diseases, Galati, Romania; \\ ${ }^{7}$ Multidisciplinary Integrative Center for \\ Dermatologic Interface Research MIC- \\ DIR, Galati, Romania
}

*These authors contributed equally to this work

\begin{abstract}
Malignant melanoma is a deadly form of skin cancer, and prompt diagnosis is a key factor in providing adequate, life-saving therapy. A 75-year-old man, with longstanding type 2 diabetes mellitus, presented with a 2- to 3-year history of right heel ulcer. He had received various therapies for a diagnosis of diabetic foot ulcer, to no avail. Physical examination showed a black, fungating ulcerated lesion on his right heel, with minimal bleeding. No inguinal lymphadenopathy was palpated. A biopsy was done, which revealed BRAF-negative malignant melanoma, with a vertical growth phase, Breslow $3.1 \mathrm{~mm}$, ulceration, $11 \mathrm{mitoses} / \mathrm{mm}^{2}$, Clark level IV, no lymphatic or vascular invasion observed. Right inguinal lymph node sampling suggested no involvement, but PET-CT suggested pulmonary, right inguinal lymph node and bone involvement. The patient was referred to the oncologists. Written informed consent for publication was given by the patient. Diabetic foot ulcers are a frequently encountered, but serious complication of diabetes mellitus. Delayed healing is often seen, despite adequate therapy. The differential diagnosis of diabetic foot ulcers is vast and includes neoplasia. When a foot ulcer fails to heal, other differential diagnoses must be considered, in order for the patient to receive adequate therapy. Here specialist consultations, including dermatology consultations, could improve chances of delivering the right therapy promptly. This is a factor underlying the emphasis on a multidisciplinary approach to foot ulcer therapy. Our presentation - reported according to the CARE guidelines - also illustrates the fact that failure to reach a timely diagnosis may deny the patient the opportunity to receive adequate treatment. In such cases, "delayed therapy becomes denied (or failed) therapy", paraphrasing the old adage "Justice delayed is justice denied".
\end{abstract}

Keywords: malignant ulcer, case report, acral malignant melanoma, diabetic foot ulcer, type 2 diabetes mellitus, delayed therapy

\section{Introduction}

Malignant melanoma is a lethal form of skin cancer. There are multiple therapeutic options for treating malignant melanoma. Surgery is preferred in the early stages and can be curative on its own. Patient education forms an essential part of preventive and therapeutic strategy, as many cases of malignant melanoma are discovered by the patients themselves. Failed therapy or delayed diagnosis can have unfortunate consequences. Diabetic foot ulcers (DFU) are a common, but serious, complication of diabetes with a worldwide prevalence of $6.3 \%{ }^{1}$ and a lifetime incidence of $25 \% .{ }^{2}$ Quite frequently patients fail to inform their doctors with regard to new lesions on their feet. Therefore, it is important for physicians to do a thorough examination of the feet, each
Correspondence: Lawrence Chukwudi Nwabudike

N. Paulescu National Institute of Diabetes, 5-7 Ion Movila Street, Sector 2 , Bucharest, Romania

Email Chukwudi.nwabudike@live.com

Cristian Onisor

Dunarea de Jos University of Galati,

Faculty of Medicine and Pharmacy, 47

Domneasca Str., Galati, 800008, Romania

Email cristi.onisor@gmail.com 
time patients present, in order to more easily detect these lesions. Some $85 \%$ of non-traumatic lower extremity amputations occur in patients with diabetes. ${ }^{3}$ The differential diagnosis of DFU is vast and includes malignancy (squamous cell carcinoma, basal cell carcinoma, Kaposi sarcoma, malignant melanoma, Merkel cell carcinoma, Mycosis fungoides), infections (deep and superficial cutaneous mycosis, mycobacterial infections), necrobiosis lipoidica, pressure ulcers, vasculopathies (warfarin-induced necrosis, Factor V Leiden deficiency, cholesterol emboli, calciphylaxis), pyoderma gangrenosum, venous ulcers, hypertensive (Martorell) ulcers. ${ }^{4}$ Diabetes itself raises the risk for skin cancer. ${ }^{5}$ This raised risk is not just due to diabetes itself, which may be generating a locus minoris resistentiae, ${ }^{6}$ ie, an underlying tendency to cancer, as seen in other immune deficiency states, ${ }^{6}$ but this increased risk for skin cancer may be associated with medications often used to treat common comorbidities of diabetes, such as hydrochlorothiazide. ${ }^{7,8}$ Some of the risk of the latter drug may be related to its potential phototoxicity. ${ }^{8}$ Without specialist, multidisciplinary input, which may help differentiate malignant from benign ulcers often by detecting subtle signs, these malignant ulcers may go undetected for long periods. ${ }^{9}$ Such cases are denied prompt and adequate therapy due to misdiagnosis or delayed diagnosis.

\section{Case Presentation}

A 75-year-old Caucasian male, with long-standing type 2 diabetes mellitus, presented with a 2- to 3-year history of painless, right heel ulcer. The ulcer had been growing gradually in size, despite adequate therapy. He had received various therapies for a diagnosis of diabetic foot ulcer, without experiencing significant improvement. Physical examination showed a black, fungating, ulcerated plaque covering his right heel, with a white fissure stretching from 12 o'clock to the middle of the lesion (Figure 1). There was minimal bleeding. No inguinal lymphadenopathy was palpated.

A biopsy was done, which revealed BRAF-negative malignant melanoma, with a vertical growth phase, Breslow $3.1 \mathrm{~mm}$, ulceration, 11 mitoses $/ \mathrm{mm},{ }^{2}$ Clark level IV, no lymphatic or vascular invasion observed. Right inguinal lymph node sampling suggested no involvement, but PET-computed tomography indicated pulmonary, right inguinal lymph node and bone involvement. A timeline detailing the various tests done is in Table 1.

The patient was referred to the oncologists.

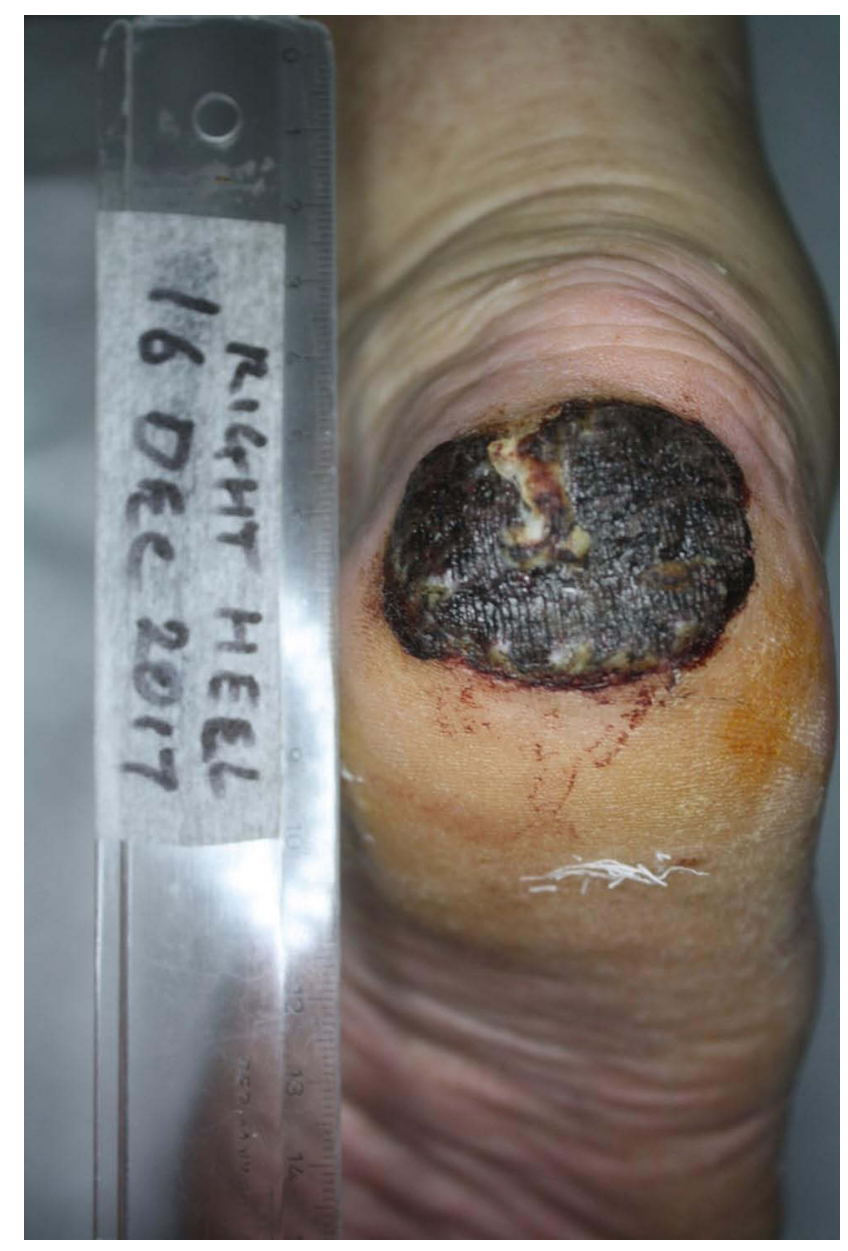

Figure I Melanoma of right heel. Right heel, with a black, well-defined plaque. There is evidence of bleeding and there is a white fissure stretching from 12 o'clock to the centre of the lesion.

\section{Discussion}

Acral lentiginous melanoma or acral melanoma was first described in 1977 by Arrington et al. ${ }^{10}$ It is the least common form of melanoma, accounting for $1-2 \%$ of cases $^{11}$ and has a lower survival rate than other forms of melanoma. ${ }^{11}$ Therefore, timely diagnosis of this form of melanoma is critical to patient survival.

Acral lentiginous melanoma is often found on the areas of the foot prone to pressure and trauma, such as the heel, lateral aspect of the foot and the forefoot, ${ }^{10}$ which are also areas in which DFU commonly present. Confusion, leading to misdiagnosis, might cause delayed diagnosis and therefore a bleaker prognosis, as in this case. Our case presented with a heel ulcer of several years duration, which, due to its location and the patient's underlying diabetes, was diagnosed and managed as a diabetic foot ulcer. Acral melanoma has also been misdiagnosed as interdigital tinea pedis, ${ }^{12}$ illustrating the vastness of the 
Table I Timeline for Tests Done

\begin{tabular}{|l|l|l|}
\hline Date & Event & Comments \\
\hline 16 Dec 2017 & $\begin{array}{l}\text { Initial patient visit, with biopsy for } \\
\text { suspected acral melanoma right foot }\end{array}$ & I8 Dec 2017, histopathology confirms acral lentiginous melanoma \\
\hline 08 Jan 2018 & Whole-body CT & Numerous uncalcified micronodules in the lungs (5-8mm diameter) \\
\hline 18 Jan 2018 & Lymphoscintigraphy & Multiple sentinel lymph nodes at right inguinal region \\
\hline 23 Jan 2018 & Right inguinal node sampling & $\begin{array}{l}\text { 3I Jan 2018, rare, scattered tumour cells (HMB45, MelanA, PanMelanoma } \\
\text { cocktail staining) }\end{array}$ \\
\hline 02 Mar 2018 & Immunohistochemistry & Reactive adenopathy, no tumours \\
\hline 12 Apr 2018 & Genetic testing & NO mutations in BRAF gene detected \\
\hline 18 Jul 2018 & Whole-body PET-CT & Active areas at right heel, right inguinal area and lungs \\
\hline 18 Jan 2019 & CT thorax and abdomen & Pulmonary nodules increased in size and number compared to previous year \\
\hline 23 Mar 2019 & PET-CT & $\begin{array}{l}\text { Progression of lesions with abdominal and thoracic lymph node involvement, as } \\
\text { well as pulmonary and leg and foot bone involvement }\end{array}$ \\
\hline
\end{tabular}

differential diagnoses of DFU. ${ }^{4,9,12}$ Failure to heal with worsening of the ulcer, despite treatment, did not appear to trigger earlier re-evaluation for a cutaneous malignancy or other differentials, perhaps because DFU are notoriously hard to heal. This difficulty in healing may be the reason why, even in a self-treating physician, melanoma was misdiagnosed and treated as a DFU. ${ }^{13}$

A referral for specialist (dermatology) care might have uncovered subtle signs that were easily missed at the primary care level. In many centres around the world, wound care is not often carried out by dermatologists, but by primary care staff, therefore such cases may "fall through the cracks". Our study is limited by the fact that it is a case study and not a large review; however, the case itself is illustrative of why the differential diagnoses of DFU must always be considered in each patient and multidisciplinary teams are necessary for adequate DFU care.

\section{Conclusion}

DFU are a common, but serious complication of diabetes. As a result, the default diagnosis of ulcers on the feet of patients suffering from diabetes is often diabetic foot ulcer. Staff, who routinely care for patients with foot ulcers need to be aware of the other differential diagnoses of DFU, including malignancy and need to be prepared to promptly refer ulcers that are not responding to adequate care. It is also necessary for dermatologists to be more involved in the care of DFU as they are uniquely placed to recognise subtle, tell-tale signs that might point to a diagnosis such as this. In such cases, failure to achieve a prompt and accurate diagnosis could deny the patient prompt and adequate therapy.

\section{Ethics and Consent}

Written informed consent for the publication of this case was provided by the patient for the publication of photographs and all test results.

Institutional approval was not required as this is a case report and the patient had already given written informed consent for the publication of photographs and all test results.

\section{Acknowledgments}

The current work was academically supported by the 'Dunarea de Jos' University of Galati, Romania, through the research center - Multidisciplinary Integrated Center of Dermatological Interface Research (MIC-DIR).

\section{Funding}

This work was supported by the "Dunarea de Jos" University of Galati, Romania.

\section{Disclosure}

The authors report no conflicts of interest in this work.

\section{References}

1. Zhang P, Lu J, Jing Y, Tang S, Zhu D, Bi Y. Global epidemiology of diabetic foot ulceration: a systematic review and meta-analysis. Ann Med. 2017;49(2):106-116. doi:10.1080/07853890.2016.1231932 
2. IDF clinical practice recommendations on the diabetic foot; 2017. Available from: https:/www.idf.org/e-library/guidelines/119-idfclinical-practice-recommendations-on-diabetic-foot-2017.html. Accessed July 2, 2020.

3. Alavi A, Sibbald RG, Mayer D, et al. Diabetic foot ulcers: part I. Pathophysiology and prevention. J Am Acad Dermatol. 2014;70 (1):1.e1-20. doi:10.1016/j.jaad.2013.06.055

4. Morton LM, Phillips TJ. Wound healing and treating wounds: differential diagnosis and evaluation of chronic wounds. $J$ Am Acad Dermatol. 2016;74(4):589-605. doi:10.1016/j.jaad.2015.08.068

5. Giovannucci E, Harlan DM, Archer MC, et al. Diabetes and cancer: a consensus report. Diabetes Care. 2010;33(7):1674-1685. doi:10.2337/ dc10-0666

6. Nwabudike LC, Tatu AL, Gambichler T, et al. Altered epigenetic pathways and cell cycle dysregulation in healthy appearing skin of patients with koebnerized squamous cell carcinomas following skin surgery. J Eur Acad Dermatol Venereol. 2019;33(1):e3-e4. doi:10.1111/jdv.15084

7. Pedersen SA, Gaist D, Schmidt SAJ, Hölmich LR, Friis S, Pottegård A. Hydrochlorothiazide use and risk of nonmelanoma skin cancer: a nationwide case-control study from Denmark. J Am Acad Dermatol. 2018;78(4):673-681.e9. doi:10.1016/j.jaad.2017.11.042
8. Tatu AL, Ciobotaru OR, Miulescu M, et al. Hydrochlorothiazide: chemical structure, therapeutic, phototoxic and carcinogenetic effects in dermatology. Rev.Chim. 2018;69(8):2110-2114. doi:10.37358/ RC.18.8.6484

9. Nwabudike LC, Gutu D. Missing the wood for the trees - A case of recalcitrant foot ulcer. Clin Exp Dermatol. 2020;46(3):562-564. doi:10.1111/ced.14455

10. Arrington JH 3rd, Reed RJ, Ichinose H, Krementz ET. Plantar lentiginous melanoma: a distinctive variant of human cutaneous malignant melanoma. Am J Surg Pathol. 1977;1(2):131-143. doi:10.1097/ 00000478-197706000-00004

11. Bradford PT, Goldstein AM, McMaster ML, Tucker MA. Acral lentiginous melanoma: incidence and survival patterns in the United States, 1986-2005. Arch Dermatol. 2009;145(4):427-434. doi:10.1001/archdermatol.2008.609

12. Silva FL, de Oliveira Rocha B, Daltro LR, Soares BFS, Fernandes JD. Acral melanoma mimicking mycotic intertrigo. Int Wound J. 2020;17:1532-1533. doi:10.1111/iwj.13394

13. Memis A, Ozturk S, Mutluoglu M, Karagoz H, Ay H. Self-treatment of foot ulcers as a risk factor for delayed diagnosis of acral melanoma. Int Wound J. 2016;13:1079. doi:10.1111/iwj.12553

\section{Publish your work in this journal}

Clinical, Cosmetic and Investigational Dermatology is an international, peer-reviewed, open access, online journal that focuses on the latest clinical and experimental research in all aspects of skin disease and cosmetic interventions. This journal is indexed on CAS.
The manuscript management system is completely online and includes a very quick and fair peer-review system, which is all easy to use. Visit http://www.dovepress.com/testimonials.php to read real quotes from published authors. 